\title{
Going online to learn health sciences research methods: The student experience
}

\author{
Lynne S Giddings \\ Auckland University of Technology \\ Shirley Campbell \\ Waitemata District Health Board \\ Peter Maclaren \\ Auckland University of Technology
}

\begin{abstract}
Health professionals are attracted to the flexibility of the virtual classroom for their on-going education. Recent studies have documented the differences in pedagogy between Internet based learning online and the traditional classroom setting, but few have investigated student health professionals' transitional process while engaged in online learning. The purpose of this mixed methods evaluation study was to document students' experience of a six month online research methods paper (unit). Specifically it explores factors that influenced student transition to online pedagogy and successful completion of the paper. Descriptive qualitative and quantitative analyses were applied to 230 student evaluations and 1720 emails collected over a four year period. The findings supported those of previous studies; the main reasons students study online is the flexibility it offers $(87 \%)$ and the ability to study without taking time off work $(72 \%)$. The student experiences were captured in the overarching theme 'from enduring to enjoying'. A teacher who works within a collaborative team, engages students early with interactive skill acquisition learning activities, and is responsive to online students' unique needs, can successfully facilitate students through the virtual classroom transitional phases: from 'virtual paralysis' to 'engagement' to 'getting into it' to 'surprised enjoyment'. Without strategies in place, however, teachers risk being overwhelmed by the onslaught of student emails, with the allotted teacher-student contact time slip sliding away.
\end{abstract}

\section{Introduction}

The virtual classroom is becoming increasingly popular as a teaching medium in universities throughout the world. Its potential role in on-going 
education for health professionals is particularly exciting as the technology meets their unique learning needs (Atack \& Rankin, 2002). The new pedagogies offer access to up to date information and allow for learner flexibility, necessities for full time employed health professionals undertaking postgraduate studies. Internet based learning online, however, challenges both teacher and students' pedagogical assumptions about what constitutes teaching and learning. These assumptions and how they shape students' self image and confidence in themselves as successful learners are often not recognised until they 'show' themselves within the online learning environment. This study documents students' experience of a six month online research methods paper (a 'paper', in New Zealand's context, is a unit of study) and the facilitating teacher's experience.

\section{Background}

A common pre-requisite for student entry into masters programs is a basic research paper. Since 1998, the Faculty of Health at Auckland University of Technology (AUT) in Aotearoa New Zealand has offered an introductory research paper for registered health professionals, including nurses, midwives, physiotherapists, occupational therapists, and psychotherapists. The paper aims to provide health professionals with an overview of the variety of research approaches available to assist them in their practice. It includes an introduction to health research paradigms, examples of commonly used methodologies and methods, and explores various issues associated with the research process such as ethical considerations and research critique. For their evaluation students complete formative assessments and submit a critique of a quantitative and a qualitative research study. The paper is offered both on site and online. The on site version is delivered face to face in classrooms over a 14 week semester, with fixed assessment points. The online version, by contrast, allows for self paced learning with monthly intakes and a six month time period for completion.

The major challenge in establishing the online version of the paper was developing pedagogical processes to enable the students to make the transition from a traditional classroom to the interactive, technologically mediated learning environment of the virtual classroom (Giddings, 2004). The online version was initiated by a teacher in the Faculty of Health in conjunction with an enthusiastic team from the Learning Technology Centre (LTC). Librarians and other learning specialists were consulted as needed. The team focused on developing an interactive learning program, which took students through a sequential learning process. Computer based activities, including games, quizzes, international web connections and real time graphics were utilised. Although students had six months to complete the paper, the average time taken was four months. The lack of 
distinct cohorts did limit the possibilities for collaborative student learning. Lacking 'chat groups', the students were encouraged by the teacher to set up a 'buddy system' with one or two others who had started during the same month. They communicated mostly by email, but some buddy groups also used telephone and/or face to face meetings. Their main online interaction, however, was one to one private emails with the teacher.

\section{Literature review}

Recent studies have explored student experiences and responses to learning within a virtual classroom (Howland \& Moore, 2002; Kearsey, 2000; Stephenson, 2001). Their findings highlight how online learning offers a very different experience from the traditional face to face classroom setting; both students and teachers have to change their pedagogical positioning, that is, how they view what is teaching and what is learning. This need for a change in attitude and way of working is often unexpected. The majority of students who choose to study online do so because of the flexibility of time and place it offers (Browne, 2003), not to learn new pedagogical approaches. Students or a teacher new to online can become frustrated when taken for granted assumptions are challenged. Online papers therefore need to be developed with this in mind (Bocchi, Eastman, \& Swift, 2004; Howland \& Moore, 2002; Yoon, 2003). To be successful, an online paper needs to creatively engage the learners so that they adapt to new ways of learning and make the most of the unique learning made possible by a virtual classroom.

\section{Three domains for success of online learning}

Yoon (2003) argues that to successfully engage an online learner, three domains need to be considered: pedagogy, technology and organisational support. These domains will be used as a framework to discuss literature that backgrounds this study.

\section{Pedagogy}

To cater for diverse student learning styles and encourage student engagement, Bocchi et al. (2004) emphasise the importance of creative interactive content and incorporation of flexible feedback. McLoughlin (2002) describes these learning strategies as intrinsic to the scaffolding for learning. The use of frequent interactive quizzes as a means of engaging students in knowledge review is advocated by Howland and Moore (2002). Yoon (2003) argues that it is the interactivity of online learning programs that can facilitate the necessary change in a person's traditional mind set, and notes that "effective online education opens unprecedented opportunities for educational interactivity" (p.29). Skilled facilitation, however, appears to be most significant in engaging students and 
structuring the learning experience. It also encourages independent learning, and the retaining of students (Bocchi et al., 2004; Browne, 2003; Simmons, Jones, \& Silver, 2004). Browne (2003) emphasises the importance of the teacher's pastoral role in this interactive medium. What is critical in ensuring student satisfaction is their active engagement in the learning process which leads to more satisfaction with the new pedagogical approach (Bocchi et al., 2004).

Technology

Technologies incorporated in online education are vast and continue to grow. Those most commonly used are: pre-recorded video and audio, chat groups, live virtual classes, simulations, online web connections, and streamed video and audio (Yoon, 2003). Yoon cautions that these technologies are only advantageous if they facilitate students' interactions, are user friendly and reliable. Technical problems appear to be a consistent frustration (Atack \& Rankin, 2002; Browne, 2003; Daugherty \& Funke, 1998). Until compatible computer hardware and software capabilities are universal, this situation may continue (Howland \& Moore, 2002). Therefore, an essential component for the success of online learning is the availability of skilled technological support (Yoon, 2003). In addition, students need to have basic computer and Internet skills prior to enrolment in an online paper. This is often overlooked. Preparation of students prior to commencement of the paper is therefore a key variable in successful online study (Yoon, 2003).

Organisational support

Students' meaningful learning experiences emerge from an integrated system which involves strong organisational support and a team approach (Bocchi et al., 2004; Chou \& Tsai, 2002; Yoon, 2003). Close collaboration between teachers, instructional designers, system developers, technical support staff, managers, administrators and learners, is necessary for effective online education (Yoon, 2003). Learner support appears linked to student satisfaction (Bocchi et al., 2004). This learner support includes access to library and learning resources, administrative assistance with admission, registration and textbook information, along with technical support during the paper (Yoon, 2003).

\section{Student characteristics for successful online learning}

A significant factor in student satisfaction and success in an online paper is what they themselves bring to the process. If students are self disciplined, motivated, and have time management and organisation skills, they are more likely to be successful online learners (Bocchi et al., 2004). Howland and Moore (2002) note that if learner expectations match paper content and process, then success is more likely; learners who rely on an authority 
"may feel abandoned without high levels of feedback and interaction with an instructor" (p. 188).

\section{Purpose of the study}

Currently there are few studies in health education literature that showcase the value of online pedagogy. With the increasing demands for continuing education for health professionals, it is critical that current programs are evaluated to ensure the best pedagogical processes are used. The question explored in this study is: What are the experiences of health professionals who are studying research methods online? The teacher's reflections on her learning while facilitating the paper will also be discussed.

\section{Methods}

This mixed method, descriptive evaluative study focused on a qualitative and quantitative analysis of students' feedback while completing an online, pre-masters health research paper. Over a four year period, 230 students completed the paper. During this time the teacher collected 1720 student emails, as well as evaluations (x2) that were completed online by students. Students were informed at the beginning and end of the paper that their data could be used for evaluative purposes and possible publication. They were asked to email the teacher if they did not want their data used. To ensure anonymity, a research assistant collated the data from semantic differentials and questionnaire evaluations. Identifying information was removed from all emails and an initial categorisation of qualitative data was carried out prior to the primary investigator (the teacher of the paper) reading any excerpts.

The qualitative data were analysed using an analytical inductive content analysis process. The email records and student online evaluations formed the basic unit of data. Each section of a record or an evaluation was systematically coded in relation to the question "what does this say about the student's experience?" and specifically "what is this description an instance of?" The codes from all data sources were then grouped and organised into sub-categories. Further categorisation formed the basis for a thematic analysis of student experiences. The QSR NVivo program enabled the retrieval, sorting, and grouping of this data. Statistical software, including SPSS and Excel was used to analyse the quantitative data from the student evaluations. Descriptive statistics were applied.

\section{Findings}

Eighty-seven percent $(87 \%)$ of the students stated that they chose to study online because of the flexibility it offered. Seventy-two percent $(72 \%)$ also 
reported that being able to study without taking time off work was an attracting factor. Three key themes emerged from the content analysis of students' experiences as presented in their emails and online survey. The overarching theme 'from enduring to enjoying' was supported with the themes 'coping with learning in multiple domains' and 'navigating life's everyday happenings' (see Table 1 and Figure 1).

Table 1: Key themes and sub-themes of student respondents' experiences

\begin{tabular}{|c|c|}
\hline \begin{tabular}{l|} 
Theme 1. \\
A passage \\
from \\
enduring to \\
enjoying
\end{tabular} & $\begin{array}{l}\text { - There was a sense of students enduring the initial phase of studying } \\
\text { research online. } \\
\text { Over time students began enjoying the research online paper. They } \\
\text { felt satisfied, relieved, pride in their accomplishments, confidence, } \\
\text { and inspired or stimulated by the knowledge they had gained. } \\
\text { - The passage from Enduring to Enjoying was facilitated by four key } \\
\text { factors. These include the sub-themes: paper teacher, educational } \\
\text { pedagogy and learning tasks, the assignments, and the learning } \\
\text { resources. }\end{array}$ \\
\hline $\begin{array}{l}\text { Sub-theme } \\
1.1 \\
\text { The paper } \\
\text { teacher }\end{array}$ & $\begin{array}{l}\text { - The paper teacher was a key factor in encouraging and facilitating } \\
\text { the students. } \\
\text { - The teacher responded to students emails usually within } 24 \text { hours, } \\
\text { generated personalised student interaction on a regular basis, and } \\
\text { gave thorough and constructive feedback on assignments. }\end{array}$ \\
\hline \begin{tabular}{l|} 
Sub-theme \\
1.2 \\
Educational \\
pedagogy \\
and \\
learning \\
tasks
\end{tabular} & $\begin{array}{l}\text { - Computer based activities, including games, quizzes, international } \\
\text { web connections and real time graphics were utilised. Of student } \\
\text { respondents: } \\
\text { - } 82 \% \text { found the program easy or very easy to use } \\
\text { - } 91 \% \text { agreed or strongly agreed that the learning outcomes were } \\
\text { - clear and comprehensive } \\
\text { - } 93 \% \text { found the quizzes helpful or very helpful to their learning } \\
\text { - } 72 \% \text { found the web references helpful or very helpful }\end{array}$ \\
\hline \begin{tabular}{|l|} 
Sub-theme \\
1.3. The \\
assignments
\end{tabular} & $\begin{array}{l}\text { Students did not find the assignments easy; however, } 91 \% \text { of } \\
\text { students found them helpful or very helpful confirming that the } \\
\text { writing process helped inform their learning. }\end{array}$ \\
\hline $\begin{array}{l}\text { Sub-theme } \\
1.4 \text { The } \\
\text { learning } \\
\text { resources }\end{array}$ & $\begin{array}{l}\text { - Students' on-line learning was supported by specific learning } \\
\text { resources. Of student respondents: } \\
\text { - } 93 \% \text { found the textbook helpful or very helpful } \\
\text { - } 73 \% \text { found the book or readings helpful or very helpful. }\end{array}$ \\
\hline $\begin{array}{l}\text { Theme } 2 \\
\text { Learning in } \\
\text { multiple } \\
\text { dimensions }\end{array}$ & $\begin{array}{l}\text { There were three areas of learning that emerged from the analysis: } \\
\text { technology competence; scholastic skills such as searching for } \\
\text { literature, writing essays and referencing; and research knowledge. }\end{array}$ \\
\hline $\begin{array}{l}\text { Theme } 3 \\
\text { Navigating } \\
\text { life's } \\
\text { everyday } \\
\text { happenings }\end{array}$ & $\begin{array}{l}\text { Many students' experienced significant life events that they had to } \\
\text { deal with in order to succeed in their online study. These included: } \\
\text { family deaths, severe illnesses and accidents, marriage break ups, } \\
\text { job changes, moving house, and many others. } \\
\text { - The two main factors that enabled the students to navigate these } \\
\text { life difficulties were the availability of the teacher and flexibility in } \\
\text { the assessment timeframes. }\end{array}$ \\
\hline
\end{tabular}




\section{From enduring to enjoying}

'From enduring to enjoying' captured the student experience of the online learning process for the majority of students over their four to six months of study. Their initial self evaluation on a semantic differential and early email messages reflected their concerns about their ability to deal with the new technology and not being in classroom learning with others, plus multiple anxieties related to learning about research; they were enduring it. As they adapted to the new pedagogy, mastering it as well as the topic, the tenor of their emails changed; there were faint hints of coming to enjoy the experience. Once the students successfully navigated their way through the tasks, exercises, and assignments, these positive feelings were more freely expressed. To unpack this theme, the notions of 'enduring' and 'enjoying' will be explored.

\section{Enduring}

A number of factors contributed to the students' initial feelings of enduring. These included: time since previous study; having to complete the paper as a requirement for entry to a program of study; lack of computer skills; anxiety and fear related to the topic of research; and a sense of being overwhelmed by the new virtual classroom language, compounded by the "jargon" of research.

Some students had been away from the academic world for a number of years and felt overwhelmed: 'This is going to be a huge learning curve as I haven't studied for 20 years". To some it was an enormous task: "I am getting there with this elephant"; "I have posted my quantitative assignment and now feel I have climbed half way up a mountain". A few students reflected frustration at the compulsory nature of the paper.

At the beginning of the paper, $12 \%$ of students had no confidence in their computer competence, $34 \%$ felt some confidence, whilst only $16 \%$ were very confident. It was therefore not surprising that some expressed anxieties about their ability with technology: "I hope I'm not the only computer virgin out there".

The majority of students at some time during their email chat with the teacher, talked about feeling anxious or daunted by the topic of research: "My main fear is statistics" noted one student, and another "I have never been able to decipher it [research]... I hope that this paper will demystify this somewhat". Email interactions between teacher and students as they progressed through the paper, showed a general movement towards feeling at least a little more comfortable with the topic: "Despite research being a scary paper I feel I've learnt a lot". 
At first, the challenge of the language used in the virtual classroom kept a number of students from accessing the paper "clicking on this and that, not really sure what I am doing." Once they were more confident with navigating the paper and the web, the language of research created most concern. It was unfamiliar to the majority of students, and they often referred to it as "jargon". Although the glossary of terms provided online assistance in "demystifying the process" they had to persevere with learning, then learning again, the meanings of words until "the penny dropped". It was a process of enduring: "like a foreign culture, using a foreign language"; "I've built this up to be such a monster in my life". A few students, however, saw it as an opportunity, "my hope is to conquer my fear, learn the language and start my Masters next year". Students were aware at the beginning of the paper that this learning would take time, 'time' as a concept appearing often in emails, mostly in relation to getting tasks completed and needing more of it: "it's taking time to get my head around all the terms"; "I'm in somewhat "panic mode' getting the assignment ready in time; "I am still working my way through the course but feel that I am running out of time".

About halfway through the set tasks, after students had completed the first assignment and received feedback, there was a shift in language: "The mud is clearing"; "I am gradually grasping the concepts". It appears that the majority of students who regularly emailed, completed the journey from 'enduring' at the beginning of the paper to 'enjoying' the online process and content at the end.

\section{Enjoying}

Arriving at a place of 'enjoying' happened for most students towards the end of the paper. They began using positive words like "satisfied", "relieved", "proud", "inspired", and "stimulated", words that reflected pride in their accomplishments and a building of confidence in their ability to manoeuvre through the language of the virtual classroom and the language of research to actually feeling capable enough to "do research". The following excerpts from their emails reflect the students' feelings: "I have come out the other side wanting to learn more", "I now feel ready and excited to take on my Masters and the research it will involve" and, "My confidence to tackle research has increased". $78 \%$ of students in the final evaluation agreed or strongly agreed that the paper met their expectations.

The journey from 'enduring' to 'enjoying' was facilitated by a number of factors: the response of the teacher; the educational pedagogy; the assignment requirements and process; and the readily available web based learning resources. 
Teacher of the paper

It was evident from email discussions and the survey feedback from students, that the teacher was a key factor in the students' successful navigation from 'enduring' to 'enjoying'. $86 \%$ of students found email contact with her helpful or very helpful. The teacher responded to students' emails in a personalised and timely manner, usually within 24 hours. Students said: "when I have had queries your prompt replies are very much appreciated"; "we are impressed by the professionalism and personalised way the course has been run" and "(Name) it is great to have you as a sounding board". The teacher's thorough, constructive and encouraging feedback on assignments also stimulated student's interactivity, quite a few students responding: "Your comments on the last assignment were constructive and most encouraging".

\section{Buddy support}

Those students, who successfully established buddy support systems within their cohort, reported that they found the collegial encouragement "very valuable" and the group provided "a safe place to off load" and "ask 'silly' questions". Groups most successful were those that had one highly committed member who tended to initiate and follow through on proposed activities, such as undertaking literature searches and sharing useful journal articles.

\section{Educational pedagogy and learning tasks}

$82 \%$ of students by the end of the paper found the web based program easy or very easy to use: "the information has been so clearly presented to both engage and educate". Students expressed enthusiasm about the paper design which helped make "a potentially 'heavy subject' far more interesting to learn than I could ever have imagined". Humorous graphics were popular as were the facilitator's personal stories: "The injection of humour, your personal experiences and the fables seemed to be a technique to humanise the computer and make it easier to bridge worlds". Overall, $91 \%$ of students agreed or strongly agreed that the learning outcomes were clear and comprehensive. Popular too were the exercises, tasks and quizzes with $93 \%$ of students finding the quizzes helpful or very helpful to their learning.

\section{Assignments and learning resources}

Two assignments were set to consolidate and evaluate the students' understanding of research. They were required to search the literature and critique a quantitative then a qualitative research study. To achieve this they needed to create a critiquing tool as part of the process. Most students (91\%) remarked that these assignments enhanced their web searching and writing skills: "I've learnt heaps through doing this assignment." Learning resources were rated very highly, including the text by Polit, Beck and 
Hungler (1997; 2001) with 93\% finding it helpful or very helpful: "I like the required text. It is easy to read and comprehensive". Books of readings (x2) were rated as helpful or very helpful by $73 \%$ of students: "the resources helped my learning and assisted understanding, and kept me on track". In addition, students frequently accessed AUT learning support and librarian staff to assist with searching for literature and writing. One student described how voluntarily attending "the session held with the AUT librarian proved invaluable when looking for literature".

\section{Coping with learning in multiple domains}

The second theme was coping with learning in multiple domains. Only $26 \%$ of students said they had studied through distance learning prior to this paper, so the majority were meeting a new pedagogy. Three areas of learning emerged from the analysis: technical competence; scholastic skills such as searching for literature, writing essays and referencing; and research knowledge.

One novice computer user described her technical skills: "as a complete dummy with computers I really did struggle at the start. The program is actually easy to use once you do overcome the first few hurdles." Another student wrote after six weeks of working on the paper: "I think I am gradually grasping the concept of studying online". Skill acquisition is reflected in the following comment: "thanks for confirming you have received my assignment. It is the first time I have attached a document to an email".

Gaining knowledge about research was the primary learning objective for the paper. Students described this learning in their communication with the teacher: "I feel more informed as a research consumer, less frightened and more interested" and "research has a whole new meaning now". The research knowledge students gained helped some of them inform their own interests. They were "inspired" and foundations were laid for their own passage to research: "I have a much clearer understanding about what qualitative research is, this is where I want to head for my thesis". As a premasters paper, this research paper had high scholastic expectations. Students referred to this process positively: "I have really enjoyed the learning even though writing it down was difficult"; "I have learnt so much about writing assignments and referencing using APA format."

\section{Navigating life's everyday happenings}

The third theme was 'navigating life's everyday happenings'. It was 'things just happening' that probably posed the most substantial barriers to success and were prominent in students' discussions in email messages. 
During the course of their study, many students' experienced significant life events: family deaths, severe illnesses and accidents, marriage break ups, job changes, moving house, and many other stress producing events. Students' own words reveal these ordeals: "the death of a spouse last semester and a recurring back problem, which is preventing long periods of sitting, have been huge hurdles for me to overcome"; "I've had a rather stressful year having moved house three times and with children issues"; "It has been a particularly stressful time with a marriage separation now on the cards"; "my wife had a cardiac pacemaker inserted after a recent heart attack so I have been somewhat distracted."

That they were able to share these personal stories reflects the relationship they had established with the teacher, who responded supportively, not only to students' personal crises, but also when they shared their difficulties in adapting to the new pedagogy and with facing their anxieties and fears concerning learning about research. Timely and personal email interaction with the teacher and some flexibility in paper assessment timeframes usually enabled the student to navigate a successful passage through these barriers. Those students who did drop out did so because of "lack of time", "didn't realise how much time it would take" and "I never really got my act into gear". A few never completed the online tasks and one student was so angry at not passing the first assignment that she left the paper. The majority of those who did not complete, however, reported feeling okay about re-starting when "the chaos resolved."

\section{Discussion}

This study supports and expands on the findings of recent research that explores the experience of online learners (Bocchi et al , 2004; Howland \& Moore, 2002; Yoon, 2003). It is the flexibility offered by learning online that first attracts health professionals. For students and teachers to have a positive experience of the virtual classroom, however, they have to transit successfully from traditional classroom pedagogy to online. The traditional classroom, where learning occurs mostly within a group with face to face communication between teachers and students, is very different from a student working at home on their own and communicating textually with a virtual teacher via a technological medium. The necessary shifts in thinking, learning style and work habits can challenge a student's self image as a learner as well as their taken for granted construction of 'that's the way it should be'. As demonstrated in previous studies, processes that purposely facilitate students through changing pedagogies need to be integrated within every stage of paper implementation (Atack \& Rankin, 2002; Bocchi et al, 2004; Browne, 2003, Howland \& Moore, 2002; Yoon, 2003). 


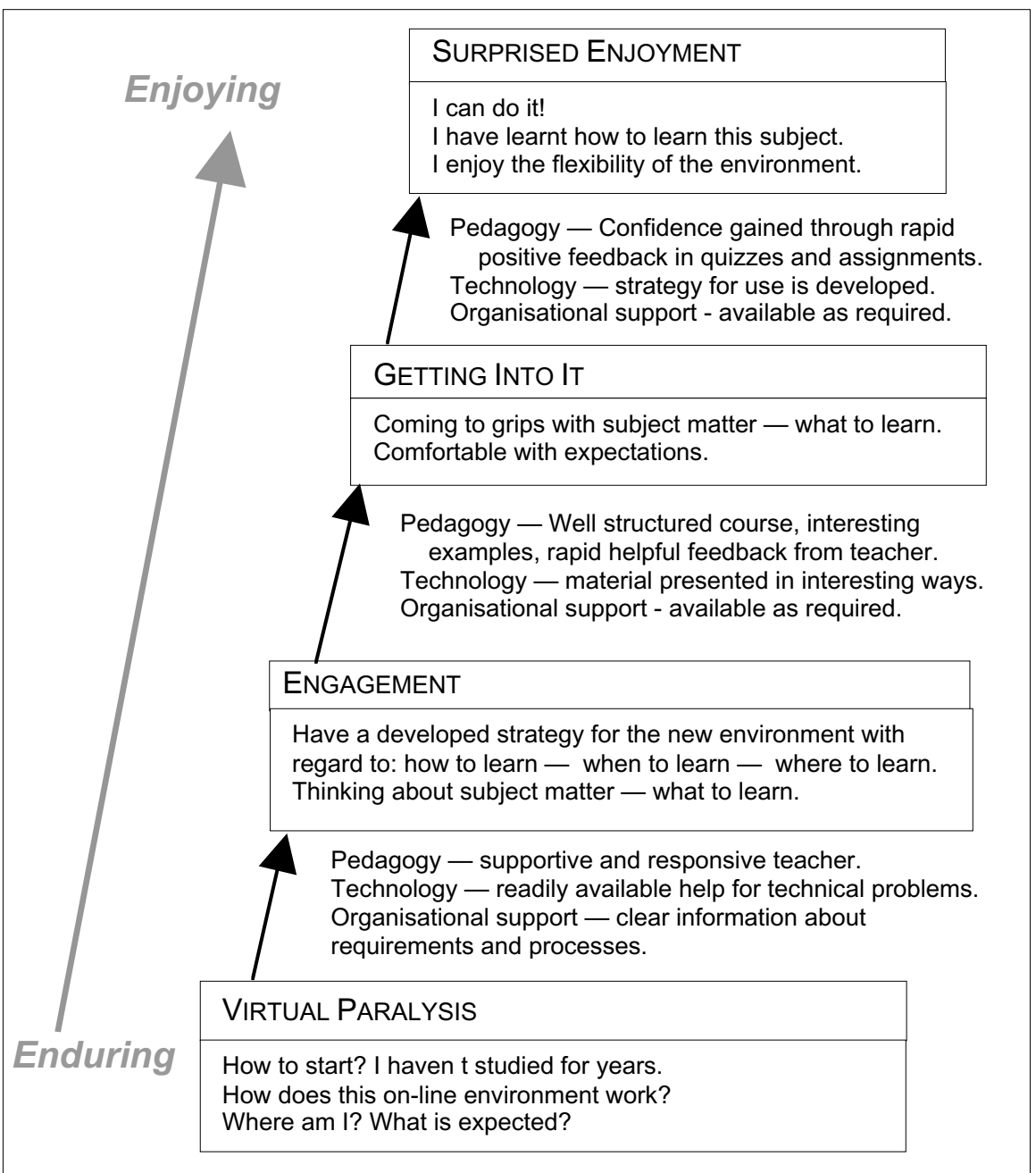

Figure 1: From enduring to enjoying: Phases in the transitional process

\section{Online students' transitional process}

The emergent themes when analysed in relation to student progression through the paper reflect a four phase transitional process, 'virtual paralysis', 'engagement', 'getting into it' and 'surprised enjoyment'. Various sub-phases represent the diversity of students' experience within each phase (see Figure 1). 
Phase One: Virtual paralysis

The majority of students appeared to go through an initial phase of 'virtual paralysis'. Their responses on the semantic differential, and discussion in emails, reflected self doubt and a lack of confidence in their ability to use computer technology to access and navigate their way through the web based online tasks. This was compounded by concerns about their ability to successfully learn research methods.

Phase Two: Engagement

It was the completion of relatively simple but interesting online tasks at the beginning of the paper that increased the students' confidence and their eventual engagement with the program. One task, to email the teacher with a personal profile and views on research, set the beginnings of the studentteacher relationship, a critical factor in keeping students on task and retaining them in the paper. In this study the teacher's commitment to answering emails ASAP (a year into offering the paper a day a week was put aside for answering student emails and updating content), putting up regular announcements, and setting up a student 'buddy' system early, were important to the engagement process. After initially being 'on call' for answering emails on a more or less daily basis the teacher gave details in paper information as to when she was and was not available and what her role was in relation to others on the team, ie. the people responsible for assisting with issues related to paper administration, getting set up, navigating the web and technology, library resourcing, and learning support. Boundary setting was important for all involved, as students online 'shout louder' than their classroom counterparts, apparently because of: the individualistic nature of online learning; the intensity of the one to one teacher-student relationship; and the 'everything seems worse when on your own late at night'. When all members of the team responded quickly to requests and referred as needed, student frustrations were kept to a minimum.

A small percentage of students (less than 5\%) did not engage in the paper and stayed in a 'fog of confusion' in relation to computer technology and research. Those that acknowledged that they had not worked on the tasks were encouraged to take an on site classroom based paper and often did so quite successfully. The virtual classroom does not suit everyone: "I learn best in the company of others"; "I like to talk out my ideas"; "I like the discipline of attending classroom sessions"; "I prefer a teacher structuring when I need to do things" or they plain "don't like it".

\section{Phase Three: Getting into it}

Those students who successfully engaged started 'getting into it'. In this phase, their concerns shifted from a focus on computer technology to the topic of the paper, research. Anxieties related to the "Big R" as one student 
termed it, loomed large in the students' communication with the teacher. Though the concerns were no different from those expressed by students in the traditional classroom setting, that is they were mystified by the research 'jargon' and challenged by the academic processes of critique and writing, students online may feel more vulnerable because they are 'on their own'. A lack of confidence if combined with poor self organisation skills compounded by the misconception that one can 'fit it around' a full time job and family commitments (and so the list goes on), can create a 'start-stop' approach to completing the tasks. It was in this working phase that 'life's everyday happenings' often took their effect. Some students 'disappeared' for a while. When they re-connected they were often well behind on the tasks; emailing to and fro frequently intensified. The teacher's emails were often words of encouragement with suggested strategies, including seeking assistance with planning and writing the first assignment. If a teacher does not re-engage the student at this time, the student is likely to become a drop out statistic. Studies have documented the higher numbers of 'did not completes' in distance and online learning programs compared with the traditional face to face classroom setting (Bocchi et al, 2004).

This study highlights the critical importance of early personal communications between the online learner and the teacher to keep them enduring. Regular 'announcements' appearing on the paper when accessed and via email encourage students to 'check in' with the teacher. A fairly immediate and personal response then reinforces that someone is 'out there' and is responsive to their needs. Once regular emailing is established, a base is created for students to share their concerns and fledgling ideas with less chance of feeling "a nuisance" or thought of as being "stupid". The lack of distinct cohorts can increase time demands on the teacher, as communication with students is primarily one to one. However maintaining an online FAQ and answer section can relieve some of this pressure on the teacher.

Phase Four: Surprised enjoyment

For most students in the study the beginning of the fourth phase of the learning on-line experience 'surprised enjoyment' happened after successful completion of the first assignment and the 19 online quizzes. Expressions of enjoying learning in a virtual classroom went hand-in-hand with a confidence that they could and would successfully complete the research paper. Once in this phase, the on-line student finds the energy to complete the work required. And it is on successful completion that they are able to reflect their pleasure at having mastered learning in multiple dimensions. 


\section{Teacher's learning through facilitating an online paper}

I had been involved as a student in an online course during my PhD study. It was more a discussion forum involving group emailing than learning online, but it introduced me to the possibilities of the virtual classroom. It also challenged my scepticism concerning the potential loss of the personal and interactive aspects of the teacher-learner and learner-learner relationships. I found I became very connected to my online group and facilitator, sight unseen. The details of my story of setting up the online paper are told elsewhere (Giddings, 2004). I will share here my most critical learning from this experience of teaching online. I learnt that just like in the classroom setting, a teacher online has to establish clear teacher-student boundaries.

Emailing is the primary form of student-teacher communication in the virtual classroom. An email from a student is immediate; it is there on the screen waiting to be opened and answered. Even if not containing a request, it is courteous and part of establishing a teacher-learner relationship to respond. I found that if I delayed answering an email for two to three days, the student would later report that they felt 'disconnected', 'alone' and for one student, 'let down'. For me, the experience was like being a frog in water that was slowly heating by degrees. I was comfortable at first with emailing more or less instantly and to and fro with students. I would check emails regularly each day and pop in to the system at weekends. As numbers increased I found I was spending one to two hours a day emailing students. Time slipped and slid away. My colleagues often assumed I 'had more time' to do research and other things as I was teaching online. It was far from the case. A year into the experience I realised that I was starting to feel overwhelmed with the emailing demands. In the classroom I knew most students by name and some things about them; a few asked questions and some stayed behind after class to talk. But online I knew a great deal more about most students - about their families, their study habits, fears, and personal happenings in their lives. They quickly came to know that I was there and that I would answer their questions more or less on tap - so they emailed. Although teacher feedback is an important contributor to students' engagement in the paper (also it was good to get the feedback "It is great to know you are there" and "You respond so quickly"), I knew that boundaries needed to be set. I decided to set up regular day when I would answer emails. I also let the students know through an announcement when I was not available. It worked. New students to the system often waited to email me on my 'emailing day'. I also developed a Frequently Asked Questions section in the paper information section - that saved repeating things. I still quite often respond immediately to a student's email, but my time is more bounded and I am able to slip slide my way to other things. 


\section{Conclusion}

This study of student feedback, collected while they were undertaking a pre-masters research paper online, showed that creating a virtual classroom is not merely a matter of putting subject content online. There are pedagogical shifts for both teachers and students: adapting to new technology for a start. The loss of the taken for granted structures and systems of the traditional classroom initially throws the confidence of new "onliners" and teachers. If processes are put in place to deal with these changes and the students become actively engaged, especially early in the paper, they are more likely to make a successful transition. To run a virtual classroom successfully, a teacher needs to be able to work in a team, be prepared for student responses during the various online learning phases, and effectively and efficiently process questions and special needs while maintaining flexibility and clear teacher-student boundaries. The pedagogical possibilities are virtually endless.

\section{Acknowledgements}

Our thanks go to the many students who volunteered their details and feedback for inclusion in this study. Also a special thank you goes to the management and staff of the Centre for Educational \& Professional Development and Faculty of Health \& Environmental Studies, Auckland University of Technology, for their continued support.

\section{References}

Atack, L. \& Rankin, J. (2002). A descriptive study of registered nurses' experiences with web-based learning. Issues and Innovations in Nursing Education, 40(4), 457465.

Bocchi, J., Eastman, J. \& Swift, C. (2004). Retaining the on-line learner: Profile of students in an on-line MBA program and implications for teaching them. Cyber Dimensions, 245-253.

Browne, E. (2003). Conversations in cyberspace: A study of on-line learning. Open Learning, 18(3), 245-259.

Chou, C. \& Tsai, C. (2002). Developing web-based curricula: Issues and challenges. Journal of Curriculum Studies, 34(6), 623-636.

Daugherty, M. \& Funke, B. (1998). University faculty and student perceptions of web-based instruction. Journal of Distance Education, 13(1), 21-39.

Giddings, L. (2004). A distance on-line learning approach to teaching research methods: A personal story. Palmerston North, New Zealand: Dunmore Press. 
Howland, J., \& Moore, J. (2002). Student perceptions as distance learners in internetbased courses. Distance Education, 23(3), 183-195.

Kearsey, G. (2000). On-line education: Learning and teaching in cyberspace. Belmont, CA: Wadsworth Thompson Learning.

McLoughlin, C. (2002). Learner support in distance and networked learning environments: Ten dimensions for successful design. Distance Education, 23(2), 149-162.

Pilot, D., Beck, C. \& Hungler. (1997). Essentials of nursing research: Methods, appraisal and utilization (4th ed.). Philadelphia: Lippincott-Raven Publishers.

Pilot, D., Beck, C., \& Hungler. (2001). Essentials of nursing research: Methods, appraisal and utilization (5th ed.). Philadelphia: Lippincott-Raven Publishers.

Simmons, S., Jones, W., \& Silver, S. (2004). Making the transition from face-to-face to cyberspace. TechTrends, 48(5), 50-85.

Stephenson, J. (2001). Teaching and learning online: New Pedagogies for new technologies. London: Kogan Page.

Yoon, S. (2003). In search of meaningful on-line learning experiences. New Directions for Adult and Continuing Education, 100, 19-30.

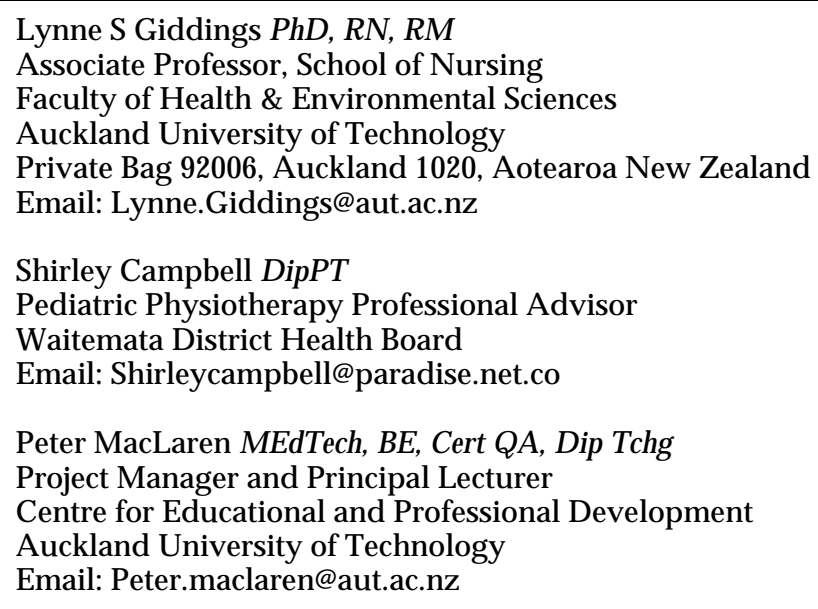

